\title{
Meta-analyses of associations of obesity with risk of melanoma and acne based on case-control studies
}

\author{
Avni Mehta and Yasha Hasija*
}

\begin{abstract}
Background: Melanoma and acne are highly prevalent dermatological diseases. A meta-analysis of case-control studies was performed to explore obesity as a risk factor for the same.

Objective: The relationship between increased BMI and melanoma incidence has been investigated in the past. We utilized recent epidemiological evidence to study this association and confirm previous findings. Moreover, to date, no meta-analysis evaluating the relationship between obesity and acne has been performed. We conducted this analysis to cast light on the same.

Methods: PubMed database was searched systematically to identify relevant literature related to the associations of obesity with risk of melanoma and acne respectively. Meta-analyses were performed using Review Manager 5.3, and the resulting risk ratios and $95 \%$ confidence intervals (Cls) were analyzed.

Results: A total of 2304 melanoma patients and corresponding 2468 controls, and 983 acne patients and corresponding 1313 controls from 5 and 4 case-control studies respectively were finally enrolled in the meta-analysis. The results showed a weak positive association between increasing BMI $\left(\geq 25 \mathrm{~kg} / \mathrm{m}^{2}\right)$ and melanoma $(\mathrm{OR}=1.36 ; 95 \% \mathrm{Cl}=1.20-1.55)$, and a null association between increasing BMI $\left(\geq 25 \mathrm{~kg} / \mathrm{m}^{2}\right)$ and acne (OR=1.27; $\left.95 \% \mathrm{Cl}=0.98-1.65\right)$.

Conclusions: The result from the first meta-analysis showed that as BMI increases, there is an increased risk of melanoma incidence. The second meta-analysis revealed the absence of any significant relationship between obesity and acne. However, larger and more high-quality studies are needed to confirm this result.
\end{abstract}

Keywords: Meta-analysis, Obesity, Melanoma, Acne, Case-control studies

\section{Key points}

- There is a need to study the impact of obesity on dermatological diseases like melanoma and acne.

- The meta-analysis revealed that people with $\mathrm{BMI} \geq 25 \mathrm{~kg} / \mathrm{m}^{2}$ are at a higher risk of melanoma than those with $\mathrm{BMI} \leq 25 \mathrm{~kg} / \mathrm{m}^{2}$.

- The meta-analysis also showed that an increase in BMI beyond $25 \mathrm{~kg} / \mathrm{m}^{2}$ did not impact acne incidence significantly.

\footnotetext{
* Correspondence: yashahasija06@gmail.com

Department of Biotechnology, Delhi Technological University, Delhi 110042 India
}

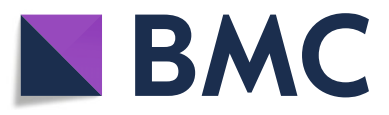

(c) The Author(s). 2019 Open Access This article is distributed under the terms of the Creative Commons Attribution 4.0 International License (http://creativecommons.org/licenses/by/4.0/), which permits unrestricted use, distribution, and

reproduction in any medium, provided you give appropriate credit to the original author(s) and the source, provide a link to the Creative Commons license, and indicate if changes were made. The Creative Commons Public Domain Dedication waiver (http://creativecommons.org/publicdomain/zero/1.0/) applies to the data made available in this article, unless otherwise stated. 
(Berenbaum et al. 2013; Bliddal et al. 2014), and sleep apnea (Tuomilehto et al. 2013).

Obesity also leads to metabolic changes that have dermatological manifestations (Guerra-Segovia and Ocampo-Candiani, 2015), but they have received minimal attention and have not been studied extensively (Yosipovitch et al. 2007). Recently, researchers have developed an interest in studying the role of obesity in psoriasis (Jensen and Skov, 2016; Carrascosa et al. 2014), but obesity is implicated in many other dermatoses as well (Tobin et al. 2013b).

Melanoma is the deadliest form of skin cancer (Ingraffea, 2013) and its incidence continues to increase worldwide at a pace much faster than any other type of solid cancer (Owens, 2014). Acne too, as evidenced by epidemiological data demonstrating a predominance of $9.4 \%$, is one of the most common skin diseases (Stein Gold, 2016) and the eighth most prevalent disease all over the world (Tan and Bhate, 2015).

A previously conducted meta-analysis (Sergentanis et al. 2013) evaluated the association between obesity and melanoma risk. However, it included case-control studies published from 1984 to 2008 . We believe that lifestyle factors have changed over the years and hence, it is important to conduct the meta-analysis again utilizing recent reports as they are better indicators of the current scenario. Moreover, no meta-analysis has been conducted so far to study the association between obesity and acne risk.

Hence, the aim of this meta-analysis was to comprehensively examine case-control studies published from 2011 to 2017 that link body mass index (BMI), a marker of obesity, with highly prevalent dermatological diseases like melanoma and acne.

\section{Methods}

\section{Search strategy}

A comprehensive literature search was performed using PubMed to evaluate the incidence of melanoma and acne in obese and overweight subjects. Our search strategy included terms of "Obesity" (e.g., "body mass index," "body surface area," "BMI," "overweight," "body weight," "obese," "diet," "adiposity," "body size"), "Melanoma" (e.g., "skin cancer," "skin neoplasm," "malignancy"), and "Acne" (e.g., "acne vulgaris," "pimple").

\section{Study selection}

All scientific papers published through 2017 were examined. Studies with insufficient data for estimating HR and $95 \% \mathrm{CI}$ were excluded, as were texts written in languages other than English and those with duplicate data. In case study populations overlapped, only the study of larger size was considered. Scientific papers that did not mention melanoma and acne were eliminated. Other studies that did not use BMI as an obesity index or involve a case-control study were also eliminated. The decision of inclusion or exclusion of each study was made independently by the investigator (A.M).

\section{Data extraction}

All candidate articles were evaluated, and data were independently extracted by the investigator (A.M.). For each study, information regarding baseline characteristics (first author's name, year of publication, country, age range, sex, number of cases and controls, sources of cases and controls, adjustment factors) was extracted. The corresponding authors were contacted at least twice in case the data required for the meta-analyses were incomplete, not available, or insufficient in the published study.

\section{Statistical analyses}

Statistical analyses were performed using Review Manager 5.3. The odd ratios (ORs) were used as a measure of the association between the particular dermatological disease and obesity. The $I^{2}$ statistic was undertaken as an objective measure to quantify the heterogeneity of the included studies. Fixed-effect meta-analysis (Mantel-Haenszel method) was performed on the studies. $P<0.1$ was indicative of the presence of clear heterogeneity and vice-versa. The condition of being overweight was defined as having BMI $\geq 25$ and $<30 \mathrm{~km} / \mathrm{m} 2$ while that of being obese was defined as having BMI $\geq 30 \mathrm{~kg} / \mathrm{m}^{2}$.

\section{Results}

\section{Study selection}

The Preferred Reporting Items for Systematic Reviews and Meta-Analyses (PRISMA) flow diagram is demonstrated in Fig. 1 to show the study selection process. Our PubMed literature search for melanoma yielded 83,083 citations, out of which 32,209 had been published during the preferable time period between 2011 and 2017. Records that were not case-control studies and did not mention the keywords related to melanoma in their title or abstract were excluded to give 114 articles that were eligible for a full-text review. All the studies were published in peer-reviewed journals. Five eligible studies (Antoniadis et al. 2011; Davies et al. 2011; Fortes et al. 2013; De Giorgi et al. 2017; Malagoli et al. 2015) were included in the final meta-analysis after excluding 108 records that had insufficient, incomplete, or irrelevant data. The data from a case-control study by Malagoli et al. (Malagoli et al. 2015) was used in another one (Malavolti et al. 2017) and hence the latter was also excluded from the meta-analysis.

Similarly, for acne, as shown in Fig. 2, a total of 1192 manuscripts were identified from PubMed, out of which 447 had been published between 2011 and 2017. An 


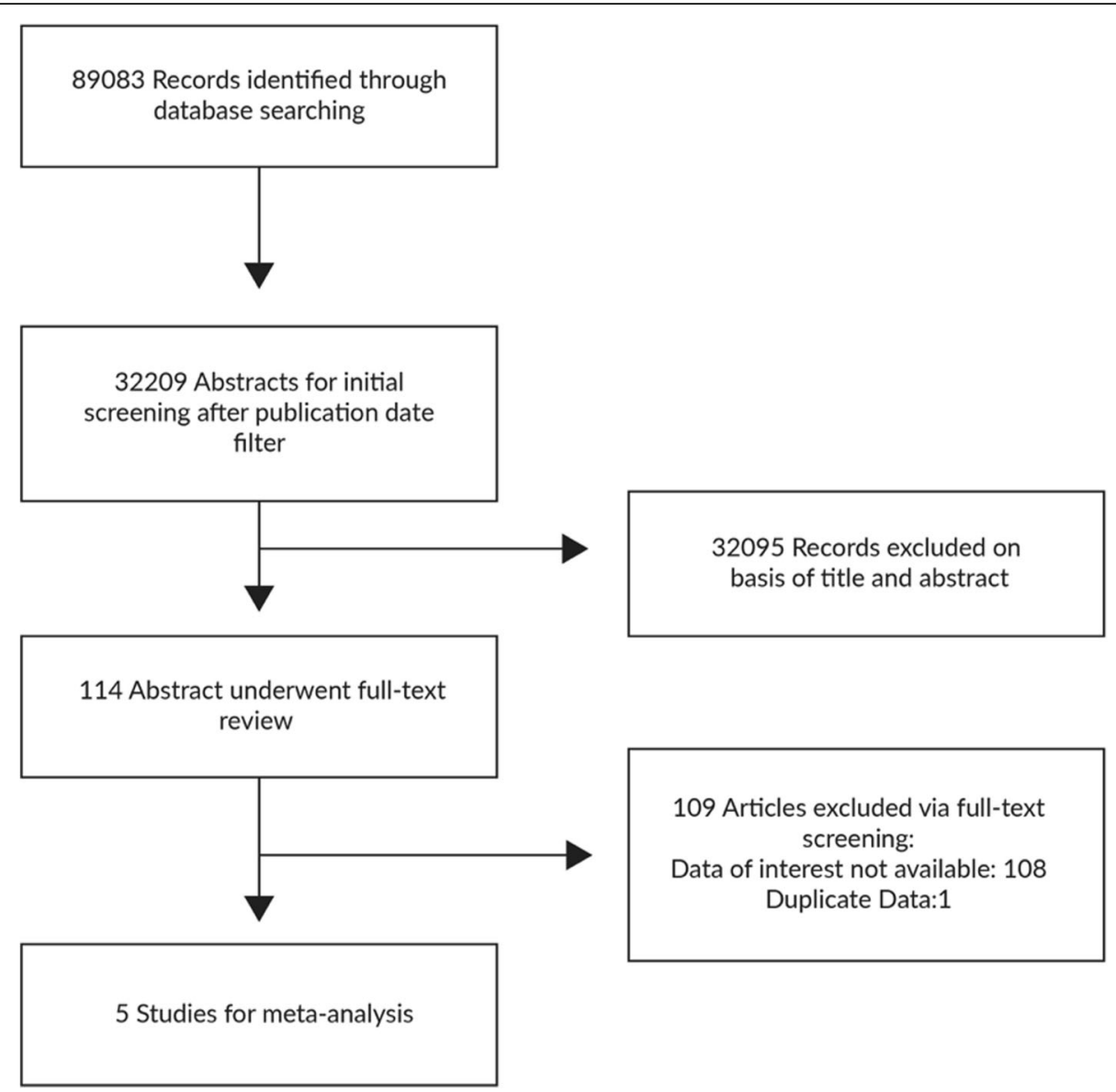

Fig. 1 Preferred Reporting Items for Systematic Reviews and Meta-Analyses flow diagram of systematic literature search and study selection for the meta-analysis in case of melanoma

additional article was identified from other sources. Records that did not mention keywords related to acne in their title or abstract were excluded along with those that did not involve case-control studies. This yielded 26 abstracts for a full-text review. Manuscripts that gave insufficient information on the effect of acne on obesity were rejected. A case-control study by Grossi et al. (Grossi et al. 2016) was also excluded from the meta-analysis since it had the same data as that by Landro et al. (Di Landro et al. 2012). After careful screening, four studies (Di Landro et al. 2012; Di Landro et al. 2016; Lu et al. 2017; Al-Shobaili et al. 2012) were selected for final inclusion in the meta-analysis. This literature search was also conducted according to PRISMA guidelines.

\section{Study characteristics}

The main characteristics of the studies included in the meta-analysis for melanoma are listed in Additional file 1. The meta-analysis included 2304 patients with melanoma and 2468 uninfected controls to study the effect of obesity on melanoma. BMI was used as an indicator of obesity. Three studies were performed in Italy, one in
Greece, and one in the UK. All the five studies were case-control studies, encompassing participants of all ages, both male and female. The studies were published from 2011 to 2017.

In case of acne, the meta-analysis included a total of 2296 participants of all ages-983 acne patients and 1313 unaffected controls. Two studies were performed in Italy, one in China, and one in Saudi Arabia. These four case-control studies were published between 2012 and 2017 and helped study the association between obesity and acne. BMI was used as an index for obesity. Barring one study that included only female participants, the rest had both male and female participants. The main characteristics of the studies included in the meta-analysis for acne are listed in Additional file 2.

\section{Association between obesity and melanoma}

Five studies were included to investigate the relationship between obesity and the risk of melanoma. Two studies reported a higher risk of melanoma in "obese and overweight people" (BMI $\geq 25 \mathrm{~kg} / \mathrm{m}^{2}$ ) while the other three did not show a significant relationship individually. The 


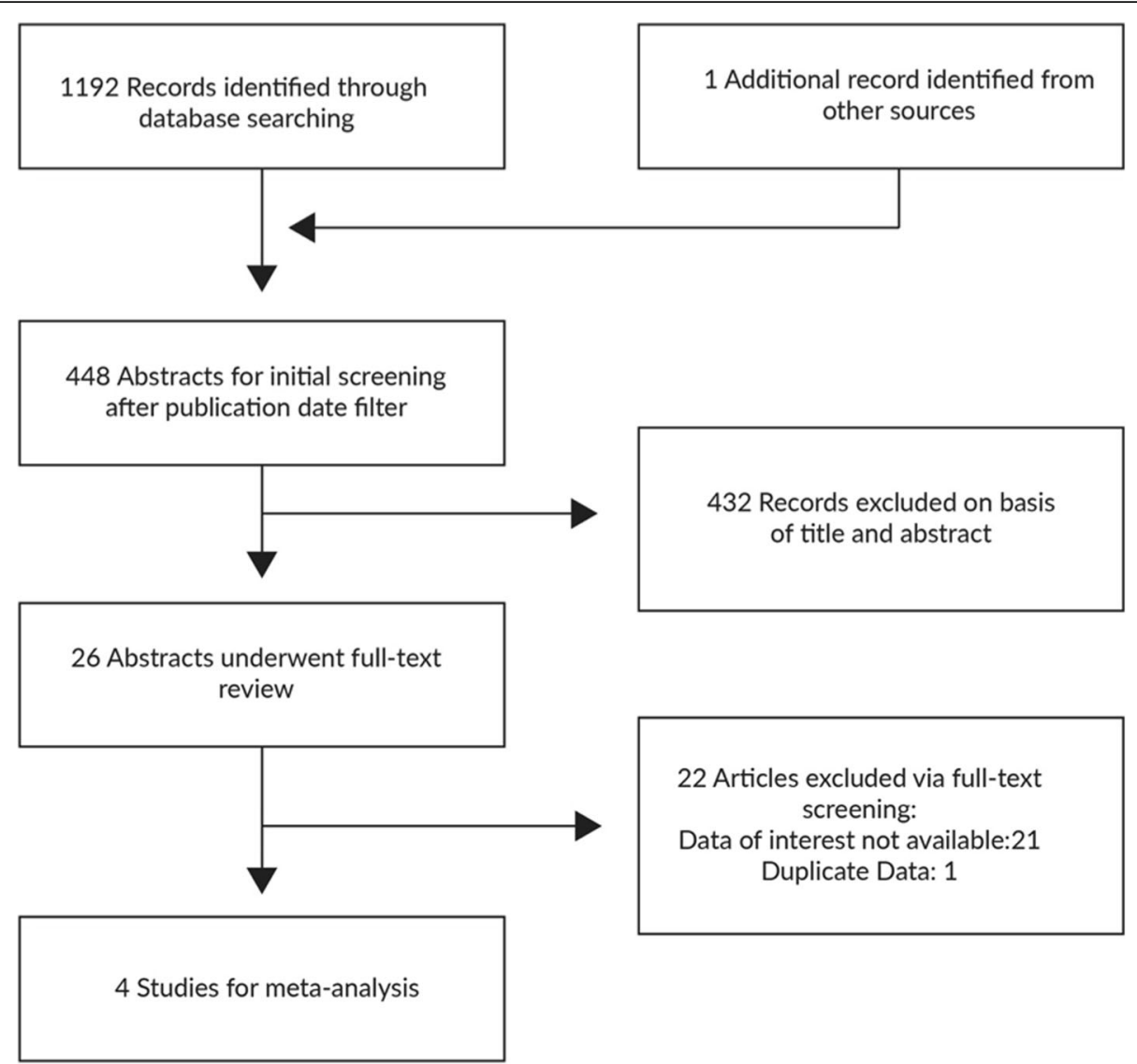

Fig. 2 Preferred Reporting Items for Systematic Reviews and Meta-Analyses flow diagram of systematic literature search and study selection for the meta-analysis in case of acne

pooled estimate was significant $(\mathrm{OR}=1.36 ; 95 \% \mathrm{CI}=1.20$ 1.55), with significant heterogeneity $\left(I^{2}=93 \% ; P<0.00001\right)$ (Fig. 3). The analyses for incidence of melanoma in overweight people $\left(25 \mathrm{~kg} / \mathrm{m}^{2} \leq \mathrm{BMI}<30 \mathrm{~kg} / \mathrm{m}^{2}\right) \quad(\mathrm{OR}=0.94$; $95 \% \mathrm{CI}=0.8-1.10)$ and obese people $\left(\mathrm{BMI} \geq 30 \mathrm{~kg} / \mathrm{m}^{2}\right)$ $(\mathrm{OR}=1.32 ; 95 \% \mathrm{CI}=1.06-1.64)$ individually have been shown in Additional file 3: Figure S1 and Additional file 4: Figure S2 respectively. The study by Grossi et al. (Grossi et al. 2016) has not been included in these individual analyses since data specific for BMI ranges $25-30 \mathrm{~kg} / \mathrm{m}^{2}$ and $\geq 30$ $\mathrm{kg} / \mathrm{m}^{2}$ was unavailable.

\section{Association between obesity and acne}

Four studies were included to investigate the relationship between obesity and the risk of acne. One study reported a higher risk of acne in obese and overweight people $\left(\mathrm{BMI} \geq 25 \mathrm{~kg} / \mathrm{m}^{2}\right)$ while the other three did not show a significant relationship individually. No significant association

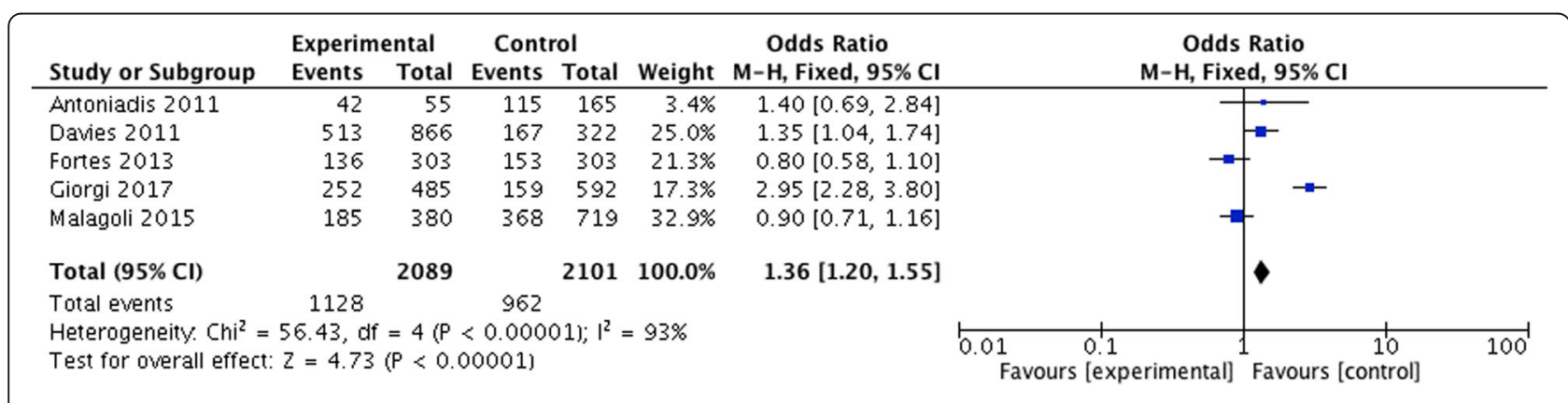

Fig. 3 Forest plot describing effect estimates for melanoma in overweight and obese people pooled together. OR odds ratio $\mathrm{Cl}$ confidence interval 
was documented after a pooled analysis $(\mathrm{OR}=1.27$; $95 \%$ $\mathrm{CI}=0.98-1.65 ; I^{2}=24 \%$ ) (Fig. 4). Meta-analyses were not conducted for overweight and obese people specifically due to the lack of sufficient data and studies.

\section{Exploration of heterogeneity}

Heterogeneity was assessed by visually studying the forest plots. Non-overlapping $\mathrm{CIs}$ and $P$ values obtained via the chi-square test were used to make the assessment. $P<0.1$ denotes statistical significance while $I^{2}>50 \%$ indicates substantial heterogeneity.

\section{Publication bias}

Since each meta-analysis includes less than 10 studies, publication bias cannot be assessed.

\section{Discussion}

This is the first meta-analysis aiming to investigate the relationship between obesity and the risk of acne and also the most recent one to include up-to-date evidence related to the association between obesity and melanoma risk.

Five studies were included to summarize the effect of obesity on the risk of melanoma. The analysis pointed to a weak positive association between increased BMI $(\geq 25$ $\left.\mathrm{kg} / \mathrm{m}^{2}\right)$ and melanoma ( $\left.\mathrm{OR}=1.36 ; 95 \% \mathrm{CI}=1.20-1.55\right)$ with significant heterogeneity between studies. This result is coherent with the result from a meta-analysis conducted in 2008 (Renehan et al. 2008) that involved cohort studies only. It is also concomitant with a meta-analysis conducted in 2011 (Sergentanis et al. 2013) in which 45\% of the studies were cohorts and the rest were case-control studies. This meta-analysis also included an unpublished case-control dataset, the numbers of which do not correspond with those in the published version (Antoniadis et al. 2011) that has been included in our meta-analysis.

For the association between obesity, indicated here by BMI $\geq 25 \mathrm{~kg} / \mathrm{m}^{2}$, and the risk of acne, four studies were studied. The meta-analysis showed a null association $(\mathrm{OR}=1.27 ; 95 \% \mathrm{CI}=0.98-1.65)$. However, in the future, more prospective, well-designed, and large-scale studies along with basic research need to be conducted to properly explore and validate the relationship between increased BMI and risk of acne.

There are several limitations to our meta-analyses. Most of them hail from the shortcomings of individual studies, but there are other factors that need to be considered as well. Firstly, the pooled studies had varying inclusion or exclusion criteria, geographical locations, sample sizes, etc. Secondly, the confounding factors were not properly adjusted in the individual case-control studies, hence subjecting the associations to confounding bias. Thirdly, the fact that only five studies were included in case of melanoma and four in case of acne point to the high probability of a publication bias. Next, the meta-analyses were constrained to articles published in PubMed, in English, and those that used body mass index as an indicator of obesity. Also, since the enrolled studies were retrospective, the meta-analysis is subject to certain methodical limitations like selection bias and information bias. Lastly, it does not give gender-specific results due to inadequate data availability. The authors of such studies were contacted at least twice for the same.

Our study has several strengths. A comprehensive literature search of PubMed was performed to study the relationship between obesity, as denoted by increased BMI, and dermatological diseases like melanoma and acne. The studies included in the meta-analysis were of high quality. Another merit of this article lies in the fact that it involves the first meta-analysis to evaluate the association between obesity and acne risk.

\section{Conclusions}

Our findings from the first meta-analysis support the notion that increased BMI has a weak positive association with incidence of melanoma. This result is congruous with previously conducted meta-analyses that evaluated a different set of studies. The second meta-analysis demonstrated a null association between obesity and acne risk. However, since this is the first meta-analysis to evaluate the relationship between increased BMI and incidence of acne, this result needs to be confirmed by future studies and meta-analyses as more literature accumulates.

\begin{tabular}{|c|c|c|c|c|c|c|c|}
\hline Study or Subgroup & \multicolumn{2}{|c|}{ Experimental } & \multicolumn{2}{|c|}{ Control } & Weight & $\begin{array}{l}\text { Odds Ratio } \\
\text { M-H, Fixed, } 95 \% \mathrm{Cl}\end{array}$ & $\begin{array}{c}\text { Odds Ratio } \\
\text { M-H, Fixed, } 95 \% \mathrm{Cl}\end{array}$ \\
\hline Landro 2012 & 22 & 205 & 33 & 358 & $21.5 \%$ & $1.18[0.67,2.09]$ & $7=$ \\
\hline Landro 2016 & 45 & 247 & 49 & 264 & $38.8 \%$ & $0.98[0.62,1.53]$ & $\rightarrow-$ \\
\hline Lu $2017^{*}$ & 46 & 364 & 20 & 295 & $19.3 \%$ & $1.99[1.15,3.44]$ & $\longrightarrow-$ \\
\hline Shobaili $2012^{* * *}$ & 20 & 164 & 39 & 390 & $20.3 \%$ & $1.25[0.70,2.22]$ & -- \\
\hline Total $(95 \% \mathrm{Cl})$ & & 980 & & 1307 & $100.0 \%$ & $1.27[0.98,1.65]$ & 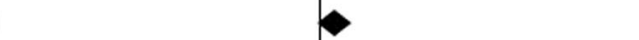 \\
\hline Total events & 133 & & 141 & & & & \\
\hline \multicolumn{7}{|c|}{$\begin{array}{l}\text { Heterogeneity. } C i^{2}=3.94, d f=3(P=0.27) ; I^{2}=24 \% \\
\text { Test for overall effect: } Z=1.82(P=0.07)\end{array}$} & $\begin{array}{ccc} & 1 & 1 \\
0.01 & 0.1 & 10 \\
& \text { Favours [experimental] } & \text { Favours [control] }\end{array}$ \\
\hline
\end{tabular}




\section{Additional files}

Additional file 1: Baseline characteristics of included studies in melanoma meta-analysis. (DOC $30 \mathrm{~kb}$ )

Additional file 2: Baseline characteristics of included studies in acne meta-analysis. (DOC 29 kb)

Additional file 3: Figure S1. Forest plot describing effect estimates for melanoma in overweight people. OR odds ratio $\mathrm{Cl}$, confidence interval. (TIFF $641 \mathrm{~kb}$ )

Additional file 4: Figure S2. Forest plot describing effect estimates for melanoma in obese people. OR odds ratio, $\mathrm{Cl}$ confidence interval. (TIFF $641 \mathrm{~kb}$ )

\section{Acknowledgements}

Not applicable.

\section{Funding}

This work has been supported by Department of Biotechnology, Government of India [No.BT/PR5402/BID/7/408/2012].

\section{Availability of data and materials}

Not applicable

\section{Authors' contributions}

$\mathrm{YH}$ conceived the idea of the study. AM designed the study. AM and $\mathrm{YH}$ wrote the manuscript. Both the authors approved the final manuscript.

\section{Ethics approval and consent to participate}

Not applicable

\section{Consent for publication}

Not applicable

\section{Competing interests}

The authors declare that they have no competing interests.

\section{Publisher's Note}

Springer Nature remains neutral with regard to jurisdictional claims in published maps and institutional affiliations.

Received: 22 November 2018 Accepted: 6 February 2019

Published online: 01 March 2019

\section{References}

Al-Shobaili HA, Salem TA, Alzolibani AA, Robaee AA, Settin AA. Tumor necrosis factor-a -308 G/a and interleukin $10-1082 \mathrm{a} / \mathrm{G}$ gene polymorphisms in patients with acne vulgaris. J Dermatol Sci. 2012;68(1):52-5.

Antoniadis AG, Petridou ET, Antonopoulos CN, Dessypris N, Panagopoulou P, Chamberland JP, et al. Insulin resistance in relation to melanoma risk. Melanoma Res. 2011;21(6):541-6.

Becton LJ, Shatat IF, Flynn JT. Hypertension and obesity: epidemiology, mechanisms and clinical approach. Indian J Pediatr. 2012;79(8):1056-61.

Berenbaum F, Eymard F, Houard X. Osteoarthritis, inflammation and obesity. Curr Opin Rheumatol. 2013;25(1):114-8.

Bliddal H, Leeds AR, Christensen R. Osteoarthritis, obesity and weight loss: evidence, hypotheses and horizons - a scoping review. Obes Rev. 2014;15(7): 578-86.

Carrascosa JM, Rocamora V, Fernandez-Torres RM, Jimenez-Puya R, Moreno JC, Coll-Puigserver $\mathrm{N}$, et al. Obesity and psoriasis: inflammatory nature of obesity, relationship between psoriasis and obesity, and therapeutic implications. Actas Dermosifiliogr. 2014;105(1):31-44.

Davies JR, Chang YM, Snowden H, Chan M, Leake S, Karpavicius B, et al. The determinants of serum vitamin $\mathrm{D}$ levels in participants in a melanoma casecontrol study living in a temperate climate. Cancer Causes Control. 2011; 22(10):1471-82.

De Giorgi V, Gori A, Savarese I, D'Errico A, Scarfi F, Papi F, et al. Role of BMI and hormone therapy in melanoma risk: a case-control study. J Cancer Res Clin Oncol. 2017;143(7):1191-7.
Di Landro A, Cazzaniga S, Cusano F, Bonci A, Carla C, Musumeci ML, et al. Adult female acne and associated risk factors: results of a multicenter case-control study in Italy. J Am Acad Dermatol. 2016;75(6):1134-1141.e1.

Di Landro A, Cazzaniga S, Parazzini F, Ingordo V, Cusano F, Atzori L, et al. Family history, body mass index, selected dietary factors, menstrual history, and risk of moderate to severe acne in adolescents and young adults. J Am Acad Dermatol. 2012;67(6):1129-35.

Fortes C, Mastroeni S, Boffetta P, Antonelli G, Pilla MA, Bottà G, et al. The protective effect of coffee consumption on cutaneous melanoma risk and the role of GSTM1 and GSTT1 polymorphisms. Cancer Causes Control. 2013; 24(10):1779-87

Garg SK, Maurer H, Reed K, Selagamsetty R. Diabetes and cancer: two diseases with obesity as a common risk factor. Diabetes Obes Metab. 2014;16(2):97-110.

Grossi E, Cazzaniga S, Crotti S, Naldi L, Di Landro A, Ingordo V, et al. The constellation of dietary factors in adolescent acne: a semantic connectivity map approach. J Eur Acad Dermatol Venereol. 2016;30(1):96-100.

Guerra-Segovia C, Ocampo-Candiani J. Skin diseases and obesity. Rev Med Inst Mex Seguro Soc. 2015;53(2):180-90.

Ingraffea A. Melanoma. Facial Plast Surg Clin North Am. 2013;21(1):33-42.

Jensen P, Skov L. Psoriasis and obesity. Dermatology. 2016;232(6):633-9.

Jokinen E. Obesity and cardiovascular disease. Minerva Pediatr. 2015:67(1):25-32.

Kelly T, Yang W, Chen CS, Reynolds K, He J. Global burden of obesity in 2005 and projections to 2030. Int J Obes. 2008;32(9):1431-7.

Lu LY, Lai HY, Pan ZY, Wu ZX, Chen WC, Ju Q. Obese/overweight and the risk of acne vulgaris in Chinese adolescents and young adults. 2017;25:5-12

Malagoli C, Malavolti M, Agnoli C, Crespi CM, Fiorentini C, Farnetani F, et al. Diet quality and risk of melanoma in an Italian population. J Nutr. 2015;145(8):1800-7.

Malavolti M, Malagoli C, Crespi CM, Brighenti F, Agnoli C, Sieri S, et al. Glycaemic index, glycaemic load and risk of cutaneous melanoma in a populationbased, case-control study. Br J Nutr. 2017;117(3):432-8.

Owens B. Melanoma. Nature. 2014;515:S109.

Park J, Morley TS, Kim M, Clegg DJ, Scherer PE. Obesity and cancer-mechanisms underlying tumour progression and recurrence. Nat Rev Endocrinol. 2014; 10(8):455-65.

Renehan AG, Tyson M, Egger M, Heller RF, Zwahlen M. Body-mass index and incidence of cancer: a systematic review and meta-analysis of prospective observational studies. Lancet. 2008;371(9612):569-78.

Sergentanis TN, Antoniadis AG, Gogas HJ, Antonopoulos CN, Adami HO, Ekbom A, et al. Obesity and risk of malignant melanoma: a meta-analysis of cohort and case-control studies. Eur J Cancer. 2013;49(3):642-57.

Stein Gold LF. Acne: What's new. Semin Cutan Med Surg. 2016;35(6 Suppl):S114-6.

Tan JK, Bhate K. A global perspective on the epidemiology of acne. Br J Dermatol. 2015:172(Suppl 1):3-12.

The GBD 2013 Obesity Collaboration, Ng M, Fleming T, Robinson M, Thomson B, Graetz N, et al. Global, regional and national prevalence of overweight and obesity in children and adults 1980-2013: a systematic analysis. Lancet. 2014; 384(9945):766-81.

Tobin AM, Ahern T, Rogers S, Collins P, O'Shea D, Kirby B. The dermatological consequences of obesity. Int J Dermatol. 2013a;52(8):927-32.

Tobin AM, Ahern T, Rogers S, Collins P, O'Shea D, Kirby B. The dermatological consequences of obesity. Int J Dermatol. 2013b;52(8):927-32.

Tuomilehto H, Seppä J, Uusitupa M. Obesity and obstructive sleep apnea_clinical significance of weight loss. Sleep Med Rev. 2013;17(5):321-9.

Yosipovitch G, DeVore A, Dawn A. Obesity and the skin: skin physiology and skin manifestations of obesity. J Am Acad Dermatol. 2007;56(6):901-16.

Ready to submit your research? Choose BMC and benefit from:

- fast, convenient online submission

- thorough peer review by experienced researchers in your field

- rapid publication on acceptance

- support for research data, including large and complex data types

- gold Open Access which fosters wider collaboration and increased citations

- maximum visibility for your research: over $100 \mathrm{M}$ website views per year

At BMC, research is always in progress.

Learn more biomedcentral.com/submissions 